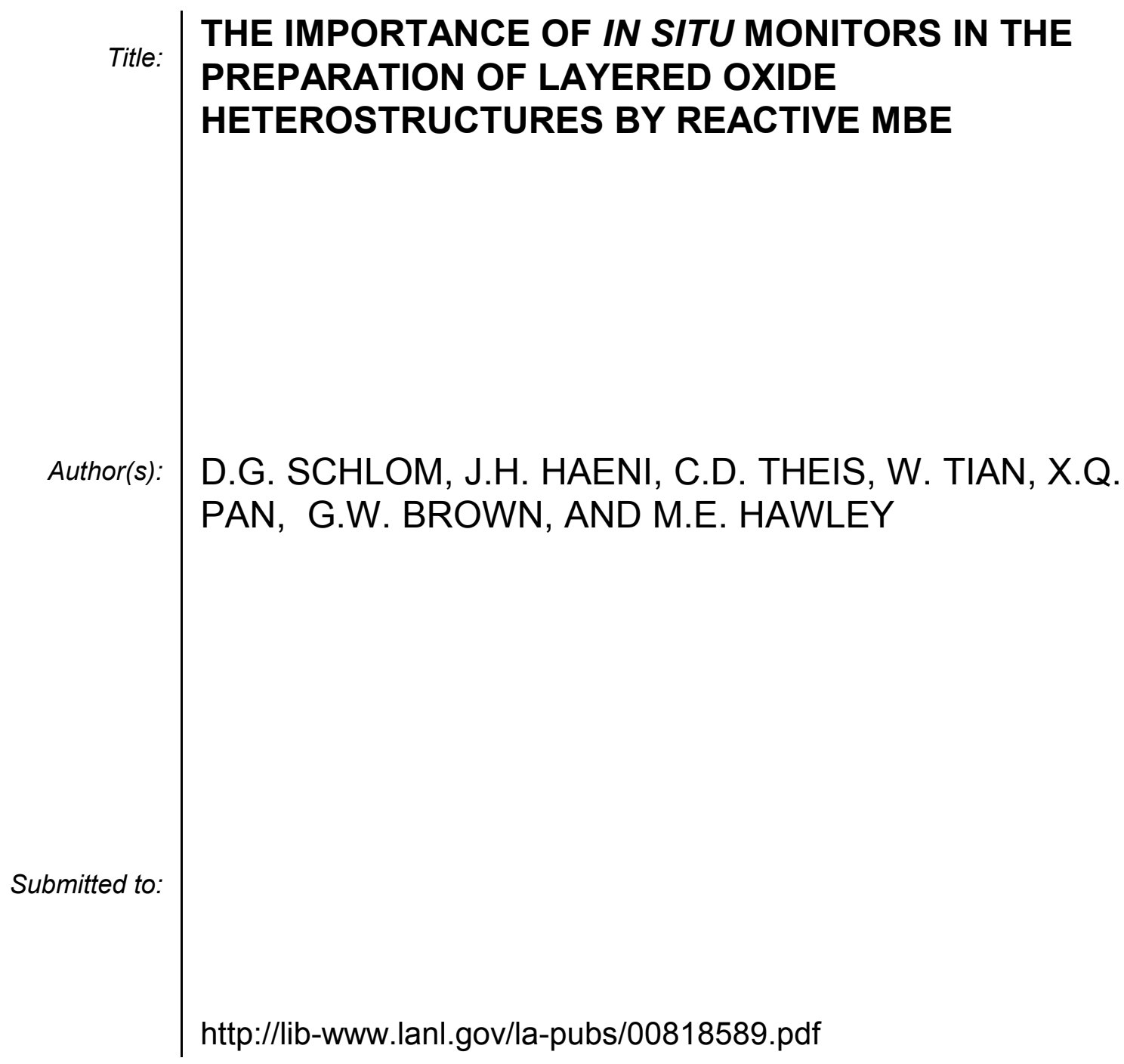




\title{
THE IMPORTANCE OF IN SITU MONITORS IN THE PREPARATION OF LAYERED OXIDE HETEROSTRUCTURES BY REACTIVE MBE
}

\author{
D.G. SCHLOM ${ }^{\dagger}$, J.H. HAENI ${ }^{\dagger}$, C.D. THEIS ${ }^{\dagger}$, W. TIAN ${ }^{\S}$, X.Q. PAN ${ }^{\S}$, G.W. BROWN*, AND \\ M.E. HAWLEY* \\ $\dagger$ Department of Materials Science and Engineering, Penn State University, University Park, PA \\ 16803-6602, schlom@ems.psu.edu \\ $\S$ Department of Materials Science and Engineering, The University of Michigan, Ann Arbor, MI \\ 48109-2136 \\ * Center for Materials Science, Los Alamos National Laboratory, Los Alamos, NM 87545
}

\section{ABSTRACT}

Using a variety of in situ monitors and when possible adsorption-controlled growth conditions, layered oxide heterostructures including new compounds and metastable superlattices have been grown by reactive molecular beam epitaxy (MBE). The heteroepitaxial layers grown include $\mathrm{Bi}_{4} \mathrm{Ti}_{3} \mathrm{O}_{12}-\mathrm{SrTiO}_{3}$ and $\mathrm{Bi}_{4} \mathrm{Ti}_{3} \mathrm{O}_{12}-\mathrm{PbTiO}_{3}$ Aurivillius phases, $\mathrm{Sr}_{n+1} \mathrm{Ti}_{n} \mathrm{O}_{3 n+1}$ RuddlesdenPopper phases, and metastable $\mathrm{PbTiO}_{3} / \mathrm{SrTiO}_{3}$ and $\mathrm{BaTiO}_{3} / \mathrm{SrTiO}_{3}$ superlattices. Accurate composition control is key to the controlled growth of such structures, and to this end combinations of reflection high-energy electron diffraction (RHEED), atomic absorption spectroscopy (AA), a quartz crystal microbalance (QCM), and adsorption-controlled growth conditions were employed during growth. The structural perfection of the films has been investigated using in situ RHEED, four-circle $\mathrm{x}$-ray diffraction, atomic force microscopy (AFM), and high-resolution transmission electron microscopy (TEM).

\section{INTRODUCTION}

Molecular beam epitaxy (MBE) has achieved unparalleled control in the integration of semiconductors at the nanometer level [1]. As we demonstrate below, its use for the integration of oxides with similar nanoscale customization appears promising. Such integration includes not only heterostructures made up of known materials, but also the creation of new materials by atomic-layer engineering. In this article we give examples of both types of integration.

Engineering oxides at the nanometer scale is particularly attractive as oxides exhibit the full spectrum of electronic, optical, and magnetic behavior: insulating, semiconducting, metallic, superconducting, pyroelectric, piezoelectric, ferroelectric, ferromagnetic, and non-linear optical effects are all contained within structurally-compatible oxides (particularly perovskites). Oxides with the perovskite crystal structure (having general formula $A B \mathrm{O}_{3}$ ) can accommodate up to $100 \%$ substitution by the majority of the elements in the periodic table on either their $A$ - or $B$-sites $[2,3]$. Such a malleable structural host offers an opportunity to customize electronic, magnetic, and optical properties in isostructural and lattice-matched thin films far beyond that possible with conventional semiconductors.

\section{EXPERIMENTAL}

Films were grown in an EPI $930 \mathrm{MBE}$ system designed for and dedicated to the growth of oxides [4]. A combination of in situ monitoring techniques including atomic absorption spectroscopy (AA) [5], reflection high-energy electron diffraction (RHEED), and a quartz crystal microbalance (QCM) was used to achieve the controlled growth of these layered oxides. Molecular beams of strontium, barium, lead, and bismuth were generated using conventional effusion cells. A titanium sublimation pump (Ti-Ball ${ }^{\mathrm{TM}}[6]$ ), powered by a precision current supply, was used as a stable and economical titanium source [7]. Oxidation was achieved using purified ozone ( $\sim 80 \%$ pure ozone at the substrate position [8]) or molecular oxygen. Ozone is required for the growth of $\mathrm{PbTiO}_{3}$ and $\mathrm{Bi}_{4} \mathrm{Ti}_{3} \mathrm{O}_{12}$ under the long mean free path conditions necessary for MBE. $\mathrm{SrTiO}_{3}$, other $\mathrm{Sr}_{n+1} \mathrm{Ti}_{n} \mathrm{O}_{3 n+1}$ phases, and $\mathrm{BaTiO}_{3}$ may be grown using molecular oxygen. For structures containing a volatile component, i.e., lead- and bismuth- 
containing films, adsorption-controlled growth conditions were used to chemically limit the incorporation of these volatile elements [9-11].

For all growths molecular beams of strontium, barium, and titanium were shuttered in a sequential manner to deliver monolayer-by-monolayer doses of atoms onto (001) $\mathrm{SrTiO}_{3}$ [12], (001) $\mathrm{LaAlO}_{3}$ [13], (110) $\mathrm{NdGaO}_{3}$, or (001) $\mathrm{LaAlO}_{3}-\mathrm{Sr}_{2} \mathrm{AlTaO}_{6}$ (LSAT) substrates. Providing the growing film surface with the correct absolute dose of species to deposit a full stoichiometric monolayer is key to the successful synthesis of many of the layered structures described. For example, achieving the phase-pure synthesis of $\mathrm{Sr}_{n+1} \mathrm{Ti}_{n} \mathrm{O}_{3 n+1}$ Ruddlesden-Popper compounds with $n=1$ to 5 required that the doses supply both the correct ratio of cations as well as the correct absolute number of atoms to complete each monolayer. If either the cation ratio or absolute dose of cations were off by more than about $1 \%$, phase-pure $\operatorname{Sr}_{n+1} \operatorname{Ti}_{n} \mathrm{O}_{3 n+1}$ phases were not attained [14].

Achieving such composition control has been a major problem in prior oxide MBE work [15]. We have met this challenge using a combination of AA (calibrated in situ using a QCM) and by monitoring the RHEED intensity oscillations that occur during the monolayer-bymonolayer deposition of $\mathrm{SrTiO}_{3}$ and $\mathrm{BaTiO}_{3}$ calibration layers. These shuttered RHEED oscillations (which are different than the conventional RHEED oscillations that occur when species are codeposited) are used to fine-tune the relative and absolute doses supplied to the substrate surface in each monolayer with an accuracy of about 1\% [16].

The films were characterized in situ by RHEED and ex situ by a Picker four-circle x-ray diffractometer, a Digital Instruments Multi-Mode atomic force microscope (AFM), and a JEOL 4000EX high-resolution transmission electron microscope (HRTEM) operated at $400 \mathrm{kV}$.

\section{RESULTS AND DISCUSSION}

\section{Metastable Superlattices and Digitally-Graded Oxide Heterostructures}

To explore the ability of MBE to integrate known oxides on a nanometer scale, we have grown epitaxial superlattices and digitally-graded structures combining $\mathrm{PbTiO}_{3}$ with $\mathrm{SrTiO}_{3}$ and $\mathrm{BaTiO}_{3}$ with $\mathrm{SrTiO}_{3}$. Both of these systems form a solid solution over their entire composition range [17,18]. Thus, $\mathrm{PbTiO}_{3} / \mathrm{SrTiO}_{3}$ as well as $\mathrm{BaTiO}_{3} / \mathrm{SrTiO}_{3}$ layered heterostructures are

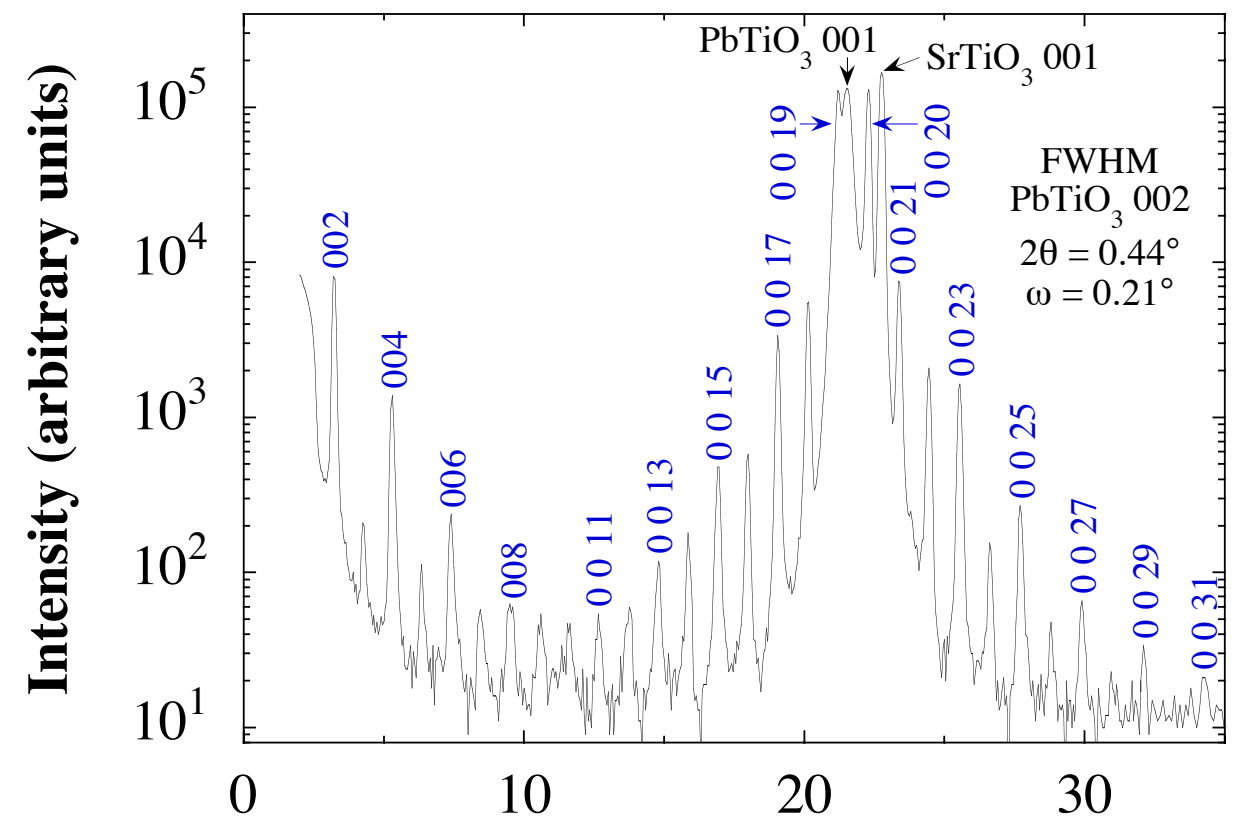

\section{$2 \theta$ (degrees)}

FIG. 1. $\theta-2 \theta$ x-ray diffraction scan of a $\left[\left(\mathrm{PbTiO}_{3}\right)_{10} /\left(\mathrm{SrTiO}_{3}\right)_{10}\right]_{15}$ superlattice. The $00 \ell$ superlattice reflections, the 001 reflection of the thick $\mathrm{PbTiO}_{3}$ buffer layer and overlayer, and 001 reflection of the $\mathrm{SrTiO}_{3}$ substrate are labeled. 
metastable; it is energetically favorable for these oxides to dissolve into each other forming $(\mathrm{Pb}, \mathrm{Sr}) \mathrm{TiO}_{3}$ and $(\mathrm{Ba}, \mathrm{Sr}) \mathrm{TiO}_{3}$ solid solutions. The metastability of $\mathrm{PbTiO}_{3} / \mathrm{SrTiO}_{3}$ and $\mathrm{BaTiO}_{3} / \mathrm{SrTiO}_{3}$ heterostructures is analogous to the situation for AlAs / GaAs heterostructures, which also form a solid solution over their entire composition range [19]. As we have reported elsewhere [20], the interface abruptness and layer thickness control for the MBE growth of $\mathrm{PbTiO}_{3} / \mathrm{SrTiO}_{3}$ superlattices is quite similar to what has been achieved for AlAs / GaAs superlattices grown by MBE [21] and MOCVD [22]. As an example, Fig. 1 shows the $\theta-2 \theta$ x-ray diffraction pattern of a $\left[\left(\mathrm{PbTiO}_{3}\right)_{10} /\left(\mathrm{SrTiO}_{3}\right)_{10}\right]_{15}$ superlattice in which a $\mathrm{PbTiO}_{3}$ layer 10 unit cells thick (in the $c$-axis direction) is grown on top of a $\mathrm{SrTiO}_{3}$ layer 10 unit cells thick (in the $c$-axis direction) and this bilayer is repeated 15 times. The x-ray diffraction data indicate that this superlattice has a periodicity of $83.7 \pm 0.2 \AA$. HRTEM images of this same superlattice corroborate the structural order and interface abruptness on a nanoscopic scale [20]. The high degree of uniformity in the structural order of the superlattice over macroscopic dimensions is revealed by the presence of all of the satellite peaks (due to the superlattice) in Fig. 1 and by the narrowness of these peaks. The full width at half-maximum (FWHM) of these peaks are comparable to the FWHM of the $\mathrm{PbTiO}_{3}$ peaks arising from the $500 \AA$ thick $\mathrm{PbTiO}_{3}$ buffer layer and overlayer that encapsulate the superlattice. $\mathrm{BaTiO}_{3} / \mathrm{SrTiO}_{3}$ superlattices with comparable perfection have also been synthesized [23].

In addition to superlattices, we have also prepared digitally-graded structures in which the average composition is varied by changing the fraction of occurrence of pure layers of the two constituents. Digital grading is commonplace in the growth of compound semiconductors by MBE. Figure 2(a) shows an example of digital grading in oxides on a comparable length scale to that used in advanced semiconductor structures. In the example shown, the composition is
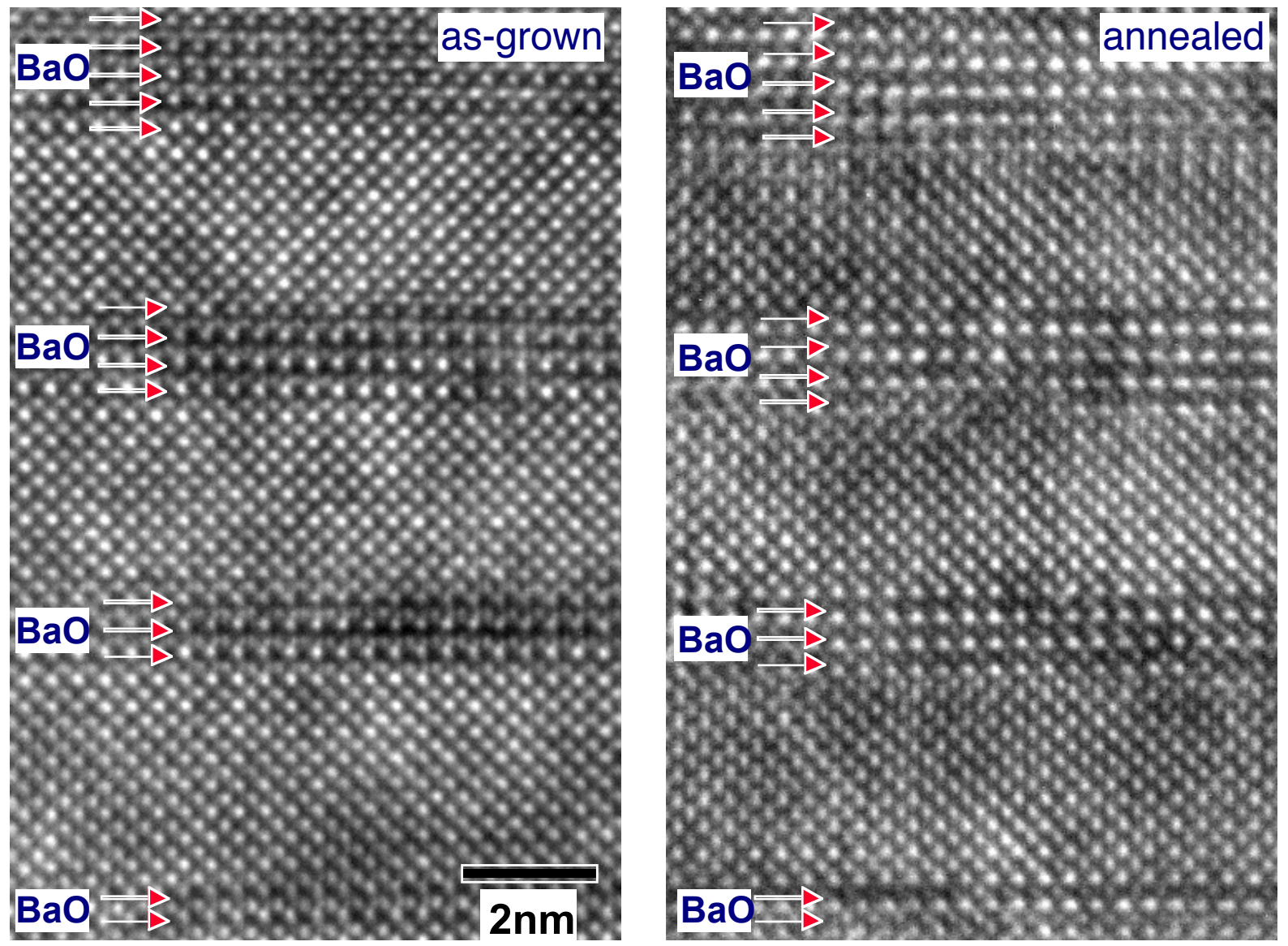

FIG. 2. HRTEM images of a digitally-graded $\mathrm{BaTiO}_{3} / \mathrm{SrTiO}_{3}$ layer that goes from pure $\mathrm{SrTiO}_{3}$ to pure $\mathrm{BaTiO}_{3}$ in unit-cell-thick increments. (a) The as-grown sample $\left(T_{\text {sub }}=660{ }^{\circ} \mathrm{C}\right)$ and (b) after annealing at $1000{ }^{\circ} \mathrm{C}$ for 2 hours in oxygen. The $\mathrm{BaO}$ monolayers in each unit-cell-thick layer of $\mathrm{BaTiO}_{3}$ are marked with arrows. As can be seen in (b), the nanoengineered layering is stable to relatively high temperatures. 
digitally graded from pure $\mathrm{SrTiO}_{3}$ to pure $\mathrm{BaTiO}_{3}$ by linearly increasing (in $10 \%$ increments) the fraction of $\mathrm{BaTiO}_{3}$ unit-cell-thick layers that occur in each segment of the structure. The grading from pure $\mathrm{SrTiO}_{3}$ begins by depositing a one unit-cell-thick (in the $c$-axis direction) $\mathrm{BaTiO}_{3}$ layer followed by a $\mathrm{SrTiO}_{3}$ layer nine unit cells thick (in the $c$-axis direction). Then comes a two unitcell-thick $\mathrm{BaTiO}_{3}$ layer followed by a $\mathrm{SrTiO}_{3}$ layer eight unit cells thick. Next a three unit-cellthick $\mathrm{BaTiO}_{3}$ layer followed by a $\mathrm{SrTiO}_{3}$ layer seven unit cells thick, ..., until a ten unit-cellthick $\mathrm{BaTiO}_{3}$ layer is deposited, completing the digital grading from pure $\mathrm{SrTiO}_{3}$ to pure $\mathrm{BaTiO}_{3}$.

Just like their oxide superlattice counterparts, these digitally-graded $\mathrm{BaTiO}_{3} / \mathrm{SrTiO}_{3}$ structures are also metastable; the equilibrium state is a $(\mathrm{Ba}, \mathrm{Sr}) \mathrm{TiO}_{3}$ solid solution. However, the rate of cation interdiffusion between the Ba-sites and $\mathrm{Sr}$-sites (both $A$-sites) in these perovskites is slow. This is apparent from Fig. 2(b), which shows an HRTEM image of a piece of the same film shown in Fig. 2(a) after it was annealed for 2 hours at $1000{ }^{\circ} \mathrm{C}$ in $1 \mathrm{~atm}$ of pure oxygen. Significant interdiffusion is only just beginning to occur under these conditions. Being able to anneal these metastable structures at such high temperatures in oxygen is advantageous in exploring the intrinsic electrical and optical properties of such customized oxide heterostructures. In their as-grown state, the electrical properties of our layered titanate films have significantly higher leakage (and dielectric loss) than after annealing. We attribute this behavior to a reduction in the concentration of oxygen vacancies.

$$
\text { (001) } \mathrm{Bi}_{4} \mathrm{Ti}_{3} \mathrm{O}_{12} /(001) \mathrm{LaAlO}_{3}
$$
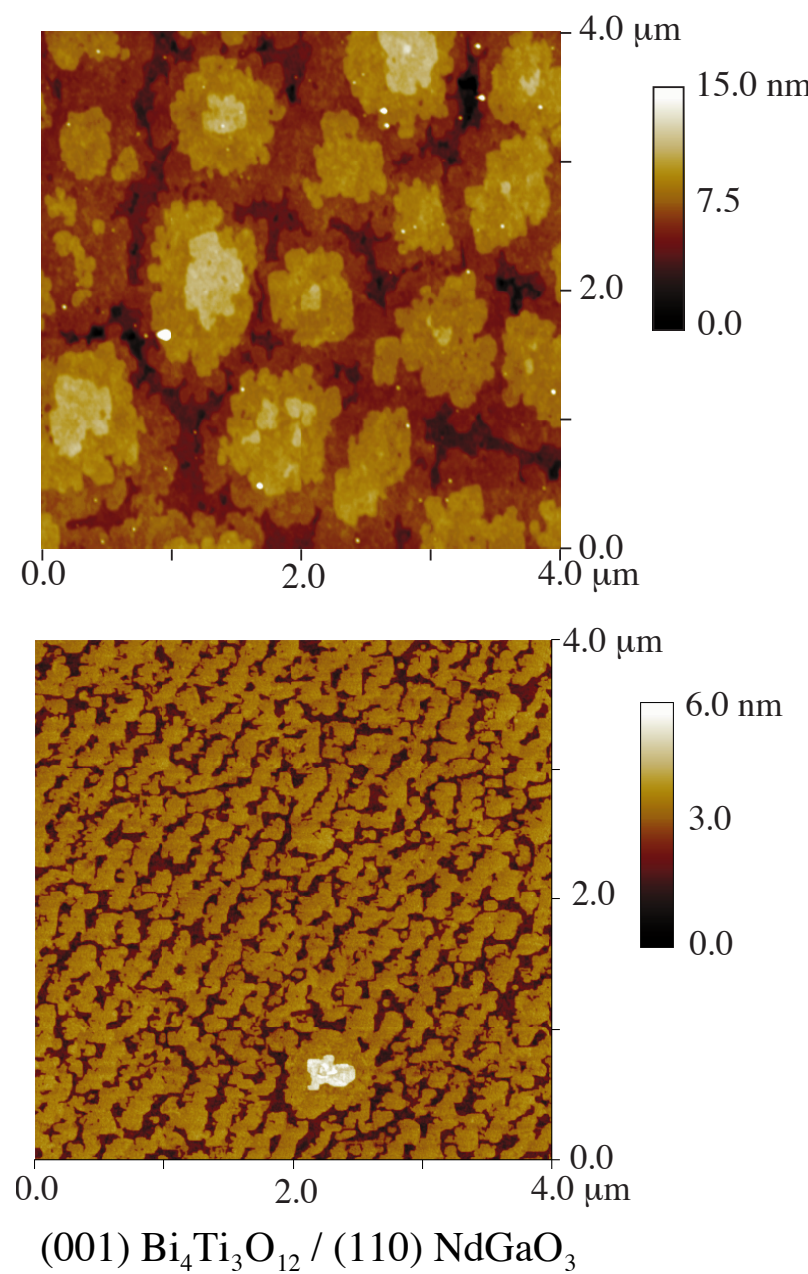

(001) $\mathrm{Bi}_{4} \mathrm{Ti}_{3} \mathrm{O}_{12} /(001) \mathrm{SrTiO}_{3}$
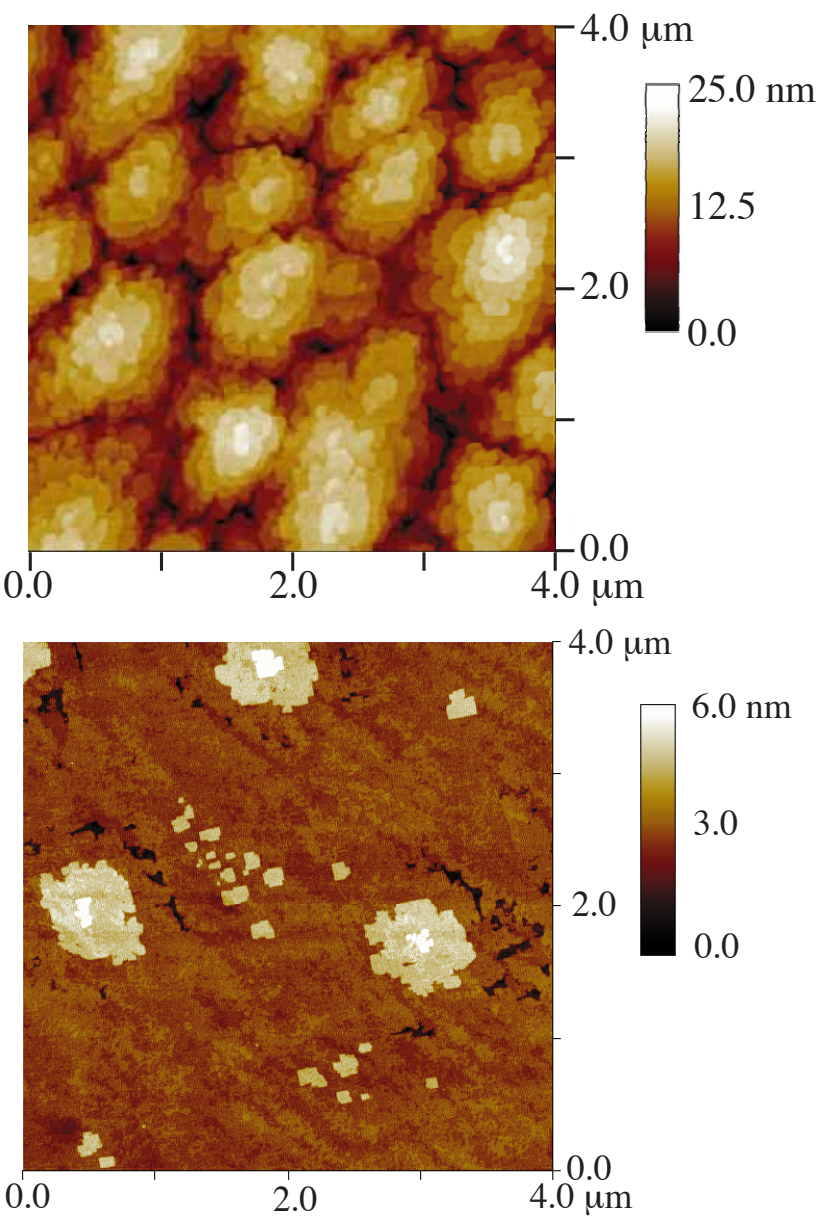

(001) $\mathrm{Bi}_{4} \mathrm{Ti}_{3} \mathrm{O}_{12} /(001)$ LSAT

FIG. 3. AFM images of the surface of epitaxial (001) $\mathrm{Bi}_{4} \mathrm{Ti}_{3} \mathrm{O}_{12}$ films grown on (001) $\mathrm{LaAlO}_{3}$, (001) $\mathrm{SrTiO}_{3}$, (110) $\mathrm{NdGaO}_{3}$, and (001) LSAT substrates. All films are between $700 \AA$ and $1000 \AA$ thick. The edges of all the images are parallel to the $<100>$ in-plane directions of the perovskite subcells of these substrates. 


\section{Superlattice Compounds}

The finest level of the layered integration of two known materials is when the layer thickness of each material contains only one formula unit. In some cases, such a superlattice is itself a known compound. Two such examples that we have prepared by reactive MBE are $\mathrm{SrBi}_{4} \mathrm{Ti}_{4} \mathrm{O}_{15}$ and $\mathrm{PbBi}_{4} \mathrm{Ti}_{4} \mathrm{O}_{15}$. The former is a superlattice of alternating formula-unit-thick layers
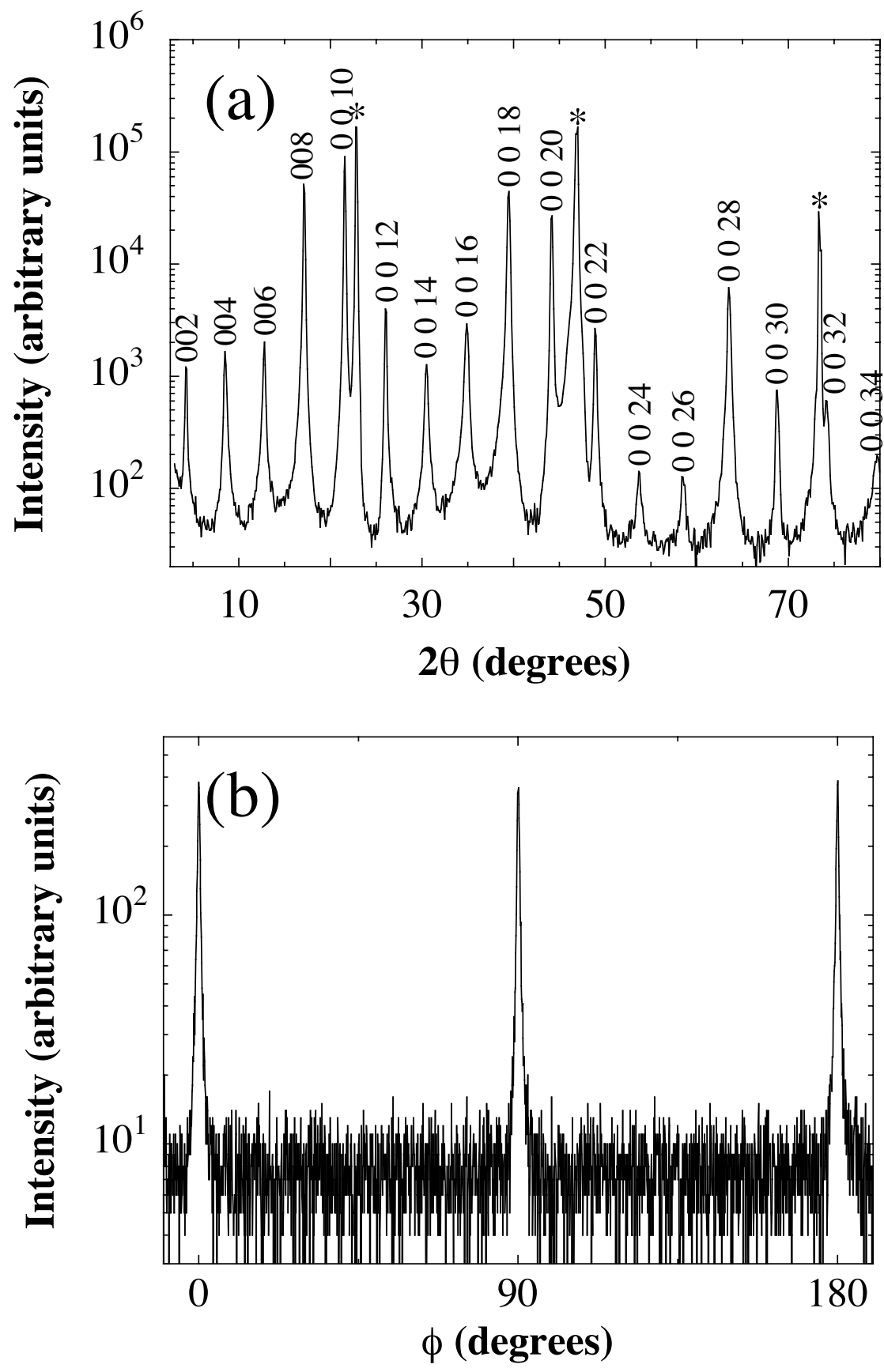

FIG. 4. X-ray diffraction scans of a $1000 \AA$ thick $c$-axis oriented epitaxial $\mathrm{SrBi}_{4} \mathrm{Ti}_{4} \mathrm{O}_{15}$ film grown on (110) $\mathrm{NdGaO}_{3}$. (a) $\theta-2 \theta$ scan in which the $00 \ell \mathrm{SrBi}_{4} \mathrm{Ti}_{4} \mathrm{O}_{15}$ reflections are labeled and the $h h 0$ reflections of the $\mathrm{NdGaO}_{3}$ substrate are marked by asterisks $(*)$. (b) $\phi$-scan of the $117 \mathrm{SrBi}_{4} \mathrm{Ti}_{4} \mathrm{O}_{15}$ reflections. $\phi=0^{\circ}$ is aligned to be parallel to the [001] in-plane direction of $\mathrm{NdGaO}_{3}$. Together these scans indicate that the $\mathrm{SrBi}_{4} \mathrm{Ti}_{4} \mathrm{O}_{15}$ film is epitaxial with lattice constants $a=5.46 \pm 0.05 \AA$ and $c=40.9 \pm 0.1 \AA$. 
of $\mathrm{Bi}_{4} \mathrm{Ti}_{3} \mathrm{O}_{12}$ and $\mathrm{SrTiO}_{3}$ and the latter is a superlattice of alternating formula-unit-thick $\mathrm{Bi}_{4} \mathrm{Ti}_{3} \mathrm{O}_{12}$ and $\mathrm{PbTiO}_{3}$ layers. These compounds are the $n=4$ members of a homologous series of structures known as Aurivillius phases [24,25] with general formulas $\mathrm{Bi}_{4} \mathrm{~Pb}_{n-3} \mathrm{Ti}_{n} \mathrm{O}_{3 n+3}$ and $\mathrm{Bi}_{4} \mathrm{Sr}_{n-3} \mathrm{Ti}_{n} \mathrm{O}_{3 n+3}$. When viewed as superlattices, these phases consist of alternating $\mathrm{Bi}_{4} \mathrm{Ti}_{3} \mathrm{O}_{12}$ and $(n-3) \mathrm{SrTiO}_{3}$ or $(n-3) \mathrm{PbTiO}_{3}$ formula-unit-thick layers, respectively. Although preparing such superlattices may seem straightforward considering the results described in the previous section for $\mathrm{PbTiO}_{3} / \mathrm{SrTiO}_{3}$ and $\mathrm{BaTiO}_{3} / \mathrm{SrTiO}_{3}$ superlattices, an important prerequisite for preparing a high-quality superlattice is that the layers grow smoothly upon one another. Unfortunately, epitaxial (001)-oriented $\mathrm{Bi}_{4} \mathrm{Ti}_{3} \mathrm{O}_{12}$ films can exhibit significant roughness. Significant roughness was observed for epitaxial $\mathrm{Bi}_{4} \mathrm{Ti}_{3} \mathrm{O}_{12}$ films grown on (001) $\mathrm{SrTiO}_{3}$ and (001) $\mathrm{LaAlO}_{3}$ substrates, as shown in the upper two AFM images of Fig. $3[9,26]$. By growing on perovskite substrates that have a better lattice match to (001) $\mathrm{Bi}_{4} \mathrm{Ti}_{3} \mathrm{O}_{12}$, smoother $\mathrm{Bi}_{4} \mathrm{Ti}_{3} \mathrm{O}_{12}$ surfaces were obtained as can be seen in the lower two AFM images in Fig. 3 [26].

Once conditions where smooth $\mathrm{Bi}_{4} \mathrm{Ti}_{3} \mathrm{O}_{12}$ films could be prepared was established, the growth of single-phase $\mathrm{SrBi}_{4} \mathrm{Ti}_{4} \mathrm{O}_{15}$ and $\mathrm{PbBi}_{4} \mathrm{Ti}_{4} \mathrm{O}_{15}$ films was achieved on (110) $\mathrm{NdGaO}_{3}$ substrates. The shuttering sequence and growth conditions used to make these superlattice compounds were similar to those used for the growth of $\mathrm{Bi}_{4} \mathrm{Ti}_{3} \mathrm{O}_{12}$ [9], except that the shuttering sequence used to deposit a one formula-unit-thick layer of $\mathrm{Bi}_{4} \mathrm{Ti}_{3} \mathrm{O}_{12}$ was immediately followed by a shuttering sequence to deposit a one formula-unit-thick layer of $\mathrm{SrTiO}_{3}$ or $\mathrm{PbTiO}_{3}$. This sequence was then repeated over and over. $\mathrm{PbBi}_{4} \mathrm{Ti}_{4} \mathrm{O}_{15}$ was grown in an adsorption-controlled regime by using a substrate temperature that lies within the overlap of the adsorption-controlled growth regime of $\mathrm{Bi}_{4} \mathrm{Ti}_{3} \mathrm{O}_{12}$ and $\mathrm{PbTiO}_{3}$. The $\theta-2 \theta$ x-ray diffraction pattern of an epitaxial $\mathrm{SrBi}_{4} \mathrm{Ti}_{4} \mathrm{O}_{15}$ film grown on a (110) $\mathrm{NdGaO}_{3}$ substrate is shown in Fig. 4(a). The FWHM of the $0018 \mathrm{SrBi}_{4} \mathrm{Ti}_{4} \mathrm{O}_{15}$ peak is $0.3^{\circ}$ in $2 \theta$ and $0.25^{\circ}$ in $\omega$ (rocking curve). These peak widths are comparable to the instrumental resolution of our four-circle diffractometer. A $\phi$-scan of the 117 $\mathrm{SrBi}_{4} \mathrm{Ti}_{4} \mathrm{O}_{15}$ peak of this same film is shown in Fig. 4(b). These peaks have a FWHM of $0.8^{\circ}$ in $\phi$.

\section{New Layered Compounds}

In addition to growing heterostructures made up of known materials, we have used reactive $\mathrm{MBE}$ to create new materials by atomic-layer engineering. An example is the phase-pure growth



FIG. 5. $n=1 \quad\left(\mathrm{Sr}_{2} \mathrm{TiO}_{4}\right), \quad n=2 \quad\left(\mathrm{Sr}_{3} \mathrm{Ti}_{2} \mathrm{O}_{7}\right), \quad n=3 \quad\left(\mathrm{Sr}_{4} \mathrm{Ti}_{3} \mathrm{O}_{10}\right), \quad n=4\left(\mathrm{Sr}_{5} \mathrm{Ti}_{4} \mathrm{O}_{13}\right), \quad n=5$ $\left(\mathrm{Sr}_{6} \mathrm{Ti}_{5} \mathrm{O}_{16}\right)$, and $n=\infty\left(\mathrm{SrTiO}_{3}\right)$ members of the Ruddlesden-Popper homologous series of compounds $\mathrm{Sr}_{n+1} \mathrm{Ti}_{n} \mathrm{O}_{3 n+1}$. $\mathrm{Ti}^{4+}$ ions lie at the center of the octahedral oxygen coordination polyhedra shown. The filled circles represent $\mathrm{Sr}^{2+}$ ions.

to be published in: Recent Developments in Oxide and Metal Epitaxy-Theory and Experiment edited by M.

Yeadon, S. Chiang, R.F.C. Farrow, J.W. Evans, and O. Auciello, Vol. 619 (Materials Research Society, Warrendale, 
of the $n=1$ to 5 members of the $\mathrm{Sr}_{n+1} \mathrm{Ti}_{n} \mathrm{O}_{3 n+1}$ homologous series, whose crystal structures are shown in Fig. 5. These compounds are known as Ruddlesden-Popper phases after the researchers who discovered the $n=1\left(\mathrm{Sr}_{2} \mathrm{TiO}_{4}\right)$ and $n=2\left(\mathrm{Sr}_{3} \mathrm{Ti}_{2} \mathrm{O}_{7}\right)$ members of this series [27]. $\mathrm{SrTiO}_{3}$, the $n=\infty$ member of this homologous series, consists of alternating $\mathrm{TiO}_{2}$ and $\mathrm{SrO}$ layers. The $n=1\left(\mathrm{Sr}_{2} \mathrm{TiO}_{4}\right)$ compound has a double $\mathrm{SrO}$ layer disrupting the perovskite network along the $c$-axis. Subsequent members of the series have an increasing number $(n)$ of perovskite blocks separating the double $\mathrm{SrO}$ layers and dimensionality intermediate between two-dimensional $\mathrm{Sr}_{2} \mathrm{TiO}_{4}(n=1)$ and three-dimensional $\mathrm{SrTiO}_{3}(n=\infty)$.

Previous attempts to synthesize $\mathrm{Sr}_{n+1} \mathrm{Ti}_{n} \mathrm{O}_{3 n+1}$ phases by conventional solid-state techniques have only been successful in making polycrystalline samples of the $n=1-3$ members [27-31]. The $\mathrm{SrO}-\mathrm{TiO}_{2}$ phase diagram illustrates the difficulties in growing single crystals or epitaxial films of this series [32,33]. Of the known $\mathrm{Sr}_{n+1} \mathrm{Ti}_{n} \mathrm{O}_{3 n+1}$ phases, only $\operatorname{SrTiO}_{3}(n=\infty)$ melts congruently. The peritectic decomposition of $\mathrm{Sr}_{2} \mathrm{TiO}_{4}(n=1)$ at $1860{ }^{\circ} \mathrm{C}$, the $\alpha \rightarrow \beta$ phase transition of $\mathrm{Sr}_{2} \mathrm{TiO}_{4}$ at $1525^{\circ} \mathrm{C}$ [33,34], and peritectoid decomposition of $\operatorname{Sr}_{3} \mathrm{Ti}_{2} \mathrm{O}_{7}(n=2)$ at $1580{ }^{\circ} \mathrm{C}$ complicate the growth of single crystals of these phases. Previous attempts to synthesize intermediate $(3<n<\infty)$ members of this series have been unsuccessful due to the degeneracy in the formation enthalpies of these members. These calculated enthalpies [35] show that there is no energetic driving force to favor the formation of one intermediate member over another. Instead, the final nanostructure of the crystal is determined by the local stoichiometry of the mixture on a nanometer scale, resulting in uncontrolled syntactic intergrowths [28]. Such

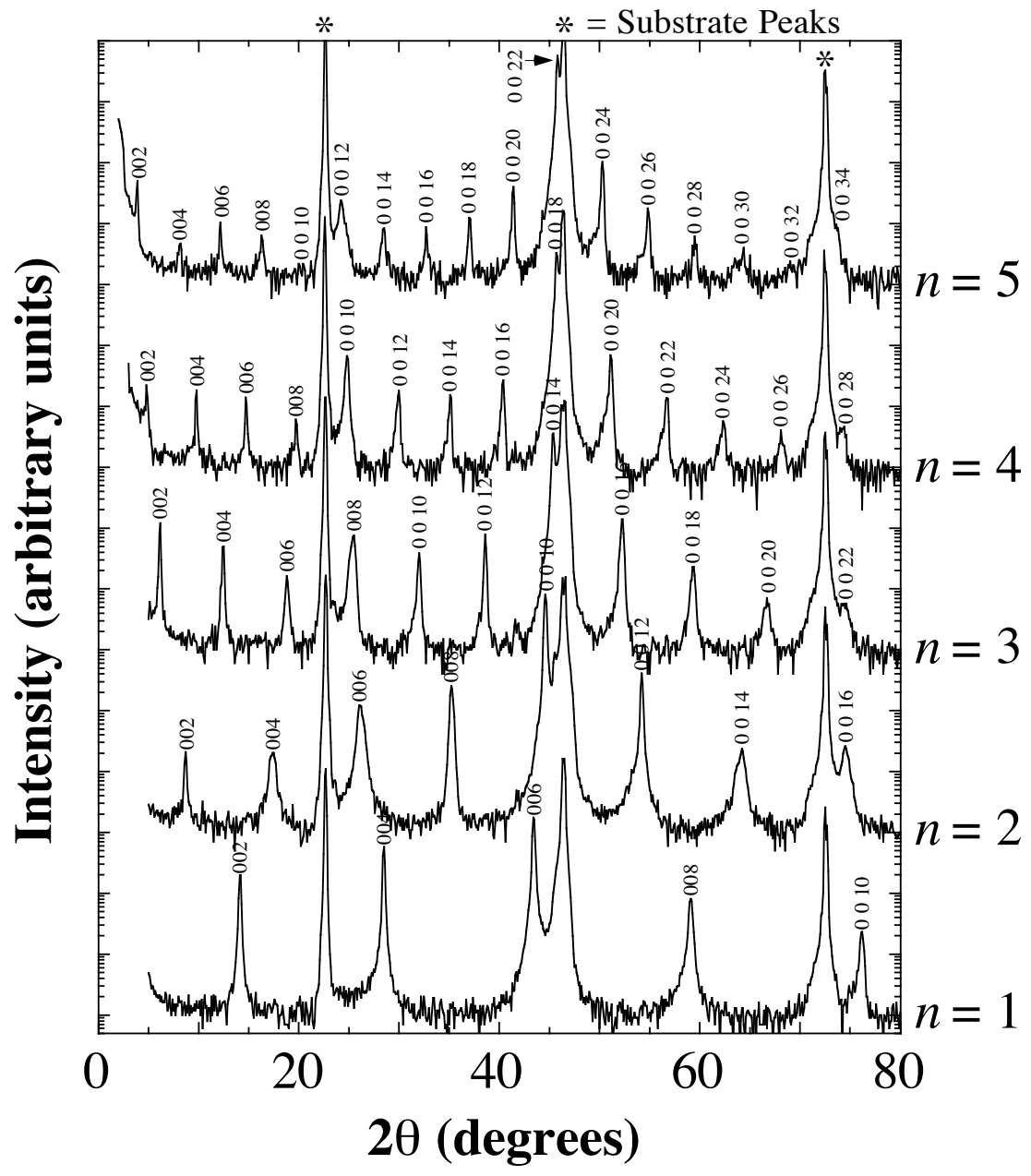

FIG. 6. $\theta-2 \theta$ x-ray diffraction scans of epitaxial films of the first five members $(n=1$ to 5$)$ of the $\mathrm{Sr}_{n+1} \mathrm{Ti}_{n} \mathrm{O}_{3 n+1}$ Ruddlesden-Popper homologous series, i.e., $\mathrm{Sr}_{2} \mathrm{TiO}_{4} \quad(n=1)$, $\mathrm{Sr}_{3} \mathrm{Ti}_{2} \mathrm{O}_{7}(n=2), \mathrm{Sr}_{4} \mathrm{Ti}_{3} \mathrm{O}_{10}(n=3), \mathrm{Sr}_{5} \mathrm{Ti}_{4} \mathrm{O}_{13}(n=4)$, and $\mathrm{Sr}_{6} \mathrm{Ti}_{5} \mathrm{O}_{16}(n=5)$. The $00 \ell$ $\mathrm{SrTiO}_{3}$ substrate peaks are marked by asterisks $(*)$. 
intergrowths inhibit the characterization of the intrinsic electronic and optical properties of individual members of these series. The layered nature of these compounds makes them ideal candidates for monolayer-by-monolayer deposition by $\mathrm{MBE}$ as we demonstrate in this work.

As the $\theta-2 \theta$ x-ray diffraction patterns in Fig. 6 show, we were able to grow epitaxial films of the first five members of the $\mathrm{Sr}_{n+1} \mathrm{Ti}_{n} \mathrm{O}_{3 n+1}$ Ruddlesden-Popper homologous series [14]. We found the phase-pure growth of these materials to be very sensitive to off-stoichiometry. X-ray diffraction is an excellent probe for spotting non-periodicity (i.e., intergrowths) in the stacking sequence in the $c$-direction. Intergrowths cause certain peaks to broaden or shift in $2 \theta$ [36,37]. All of the peaks in Fig. 6 show narrow widths and the correct $2 \theta$ positions. $\phi$-scans of all the $n$
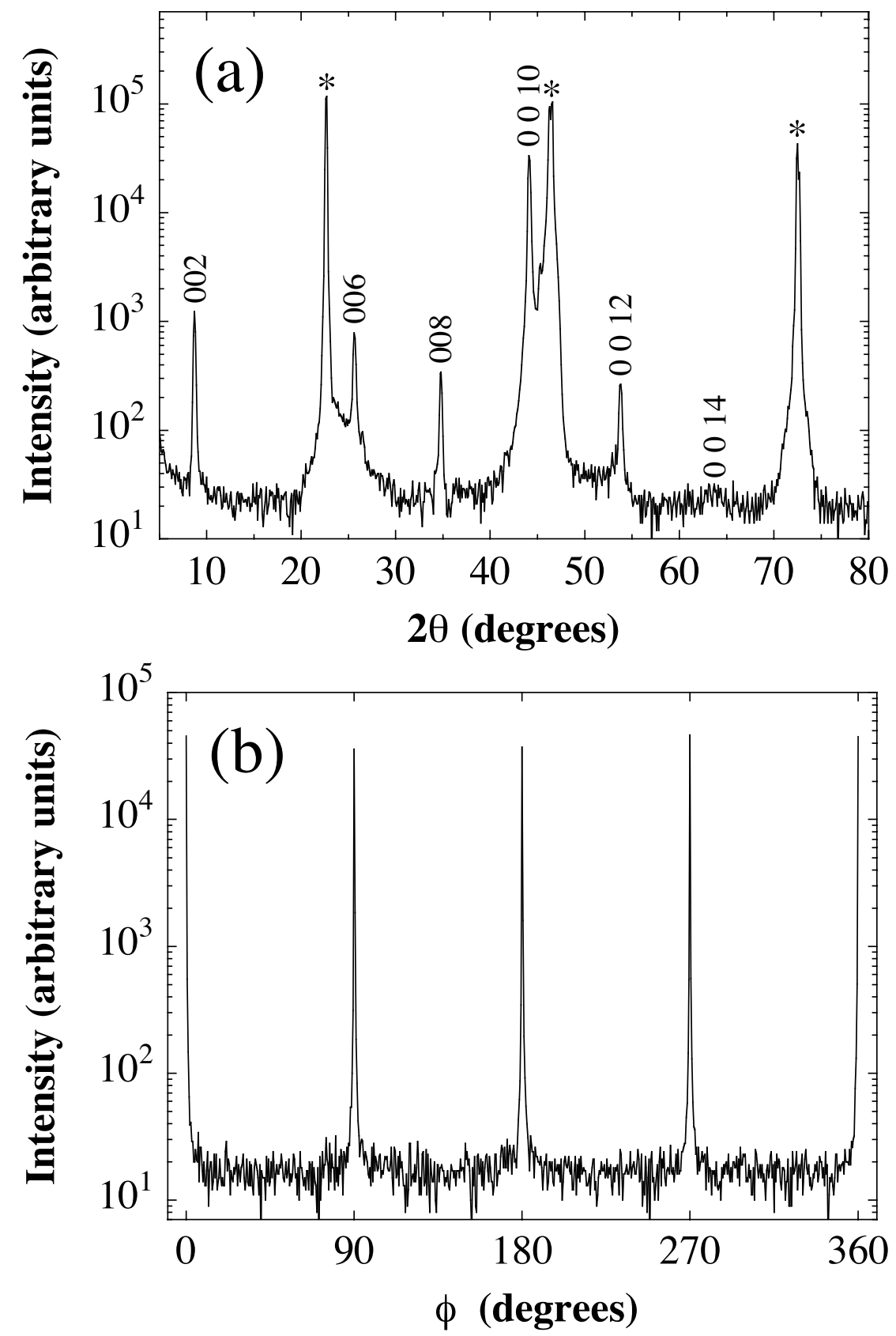

FIG. 7. X-ray diffraction scans of a $400 \AA$ thick $c$-axis oriented epitaxial $\mathrm{BaSr}_{2} \mathrm{Ti}_{2} \mathrm{O}_{7}$ film grown on (001) $\mathrm{SrTiO}_{3}$. (a) $\theta-2 \theta$ scan in which the $00 \ell \mathrm{BaSr}_{2} \mathrm{Ti}_{2} \mathrm{O}_{7}$ reflections are labeled and the $00 \ell$ reflections of the $\mathrm{SrTiO}_{3}$ substrate are marked by asterisks $(*)$. (b) $\phi$-scan of the $105 \mathrm{BaSr}_{2} \mathrm{Ti}_{2} \mathrm{O}_{7}$ reflections. $\phi=0^{\circ}$ is aligned to be parallel to the [010] in-plane direction of $\mathrm{SrTiO}_{3}$. Together these scans indicate that the $\mathrm{BaSr}_{2} \mathrm{Ti}_{2} \mathrm{O}_{7}$ film is epitaxial with lattice constants $a=3.95 \pm 0.04 \AA$ and $c=20.2 \pm 0.1 \AA$. 
members grown indicate that the films are oriented with the epitaxial relationship (001) $\mathrm{Sr}_{n+1} \mathrm{Ti}_{n} \mathrm{O}_{3 n+1} \|(001) \mathrm{SrTiO}_{3}$ and [010] $\mathrm{Sr}_{n+1} \mathrm{Ti}_{n} \mathrm{O}_{3 n+1}$ II [010] $\mathrm{SrTiO}_{3}$ [14,38]. Although the $n=1-3$ members of this series have been grown by bulk methods (in polycrystalline form) [27-31], this is the first thin film growth of these materials and the first report of phase-pure $n=4$ and $n=5$ phases in any form. We have studied the defect structure of these phases using HRTEM [38] as well as their dielectric properties [14].

As a final example involving the customization of layering at the atomic-layer level, we discuss the synthesis of a new metastable layered compound, $\mathrm{BaSr}_{2} \mathrm{Ti}_{2} \mathrm{O}_{7}$. This is an $n=2$ Ruddlesden-Popper phase (see Fig. 5) with barium completely substituting for the strontium in the perovskite layer. The resulting layered structure contains a unit cell of $\mathrm{BaTiO}_{3}$ sandwiched between double SrO layers. Although Ruddlesden-Popper phases exist for a wide variety of ions [39], no Ruddlesden-Popper homologous series is known that contains ferroelectric members. $\mathrm{BaSr}_{2} \mathrm{Ti}_{2} \mathrm{O}_{7}$ is an example in which the ferroelectric perovskite $\mathrm{BaTiO}_{3}$ is incorporated (by artificial means) into a Ruddlesden-Popper structure. No stable phase with composition $\mathrm{BaSr}_{2} \mathrm{Ti}_{2} \mathrm{O}_{7}$ is known; this composition resides in a two-phase region in the $\mathrm{BaO}-\mathrm{SrO}-\mathrm{TiO}_{2}$ pseudoternary phase diagram $[18,30]$. These two phases from the phase diagram are $(\mathrm{Ba}, \mathrm{Sr}) \mathrm{TiO}_{3}$ and $(\mathrm{Ba}, \mathrm{Sr})_{2} \mathrm{TiO}_{4}$. However, evidence of the formation of $\mathrm{Ba}_{n+1} \mathrm{Ti}_{n} \mathrm{O}_{3 n+1}$ Ruddlesden-Popper homologous phases at the surface of polycrystalline $\mathrm{BaTiO}_{3}$ samples has been reported $[40,41]$, indicating that the energetics of formation of such phases are not too energetically unfavorable. We have synthesized the desired metastable $\mathrm{BaSr}_{2} \mathrm{Ti}_{2} \mathrm{O}_{7}$ phase through the use of epitaxial stabilization-the use of interfacial energy to favor the desired metastable phase over the equilibrium phase [42-,43,44].

The $\theta-2 \theta$ x-ray diffraction pattern of an epitaxial $\mathrm{BaSr}_{2} \mathrm{Ti}_{2} \mathrm{O}_{7}$ film grown on a (001) $\mathrm{SrTiO}_{3}$ substrate is shown in Fig. 7(a). The FWHM of the $0010 \mathrm{BaSr}_{2} \mathrm{Ti}_{2} \mathrm{O}_{7}$ peak is $0.25^{\circ}$ in $2 \theta$. A $\phi$-scan of the $105 \mathrm{BaSr}_{2} \mathrm{Ti}_{2} \mathrm{O}_{7}$ peak of this same film is shown in Fig. 7(b). These peaks have a FWHM of $0.4^{\circ}$ in $\phi$. No evidence of the two phases expected from the phase diagram $[18,30]$, i.e., $(\mathrm{Ba}, \mathrm{Sr}) \mathrm{TiO}_{3}$ or $(\mathrm{Ba}, \mathrm{Sr})_{2} \mathrm{TiO}_{4}$, is present in the diffraction data.

$\mathrm{BaSr}_{2} \mathrm{Ti}_{2} \mathrm{O}_{7}$ is the first member of a homologous series of phases with general formula $\mathrm{Sr}_{2} \mathrm{TiO}_{4}\left(\mathrm{BaTiO}_{3}\right)_{n}$. For applied electric fields up to about $10^{6} \mathrm{~V} / \mathrm{cm}$ applied along the $c$-axis we saw no evidence of a switchable polarization in these epitaxial $\mathrm{BaSr}_{2} \mathrm{Ti}_{2} \mathrm{O}_{7}$ films. By synthesizing additional members of this series and probing their dielectric and possibly ferroelectric response, we intend to study the effect of dimensional confinement on the properties of oxide ferroelectrics.

\section{CONCLUSIONS}

Using a variety of in situ monitors and when possible adsorption-controlled growth conditions, we have demonstrated that reactive $\mathrm{MBE}$ is capable of customizing the layering of dielectric and ferroelectric oxides with nanometer precision. Such customized layering can involve the integration of existing materials, e.g., $\mathrm{PbTiO}_{3}, \mathrm{BaTiO}_{3}, \mathrm{SrTiO}_{3}$, and $\mathrm{Bi}_{4} \mathrm{Ti}_{3} \mathrm{O}_{12}$, to create metastable superlattices, digitally-graded heterostructures, and layered phases. Customizing the layering of oxides at the sub-unit-cell level is also possible and has led to the creation of new materials: energetically degenerate $\mathrm{Sr}_{n+1} \mathrm{Ti}_{n} \mathrm{O}_{3 n+1}$ phases and metastable $\mathrm{Sr}_{2} \mathrm{TiO}_{4}\left(\mathrm{BaTiO}_{3}\right)_{n}$ phases. Accurate composition control is key to the controlled growth of such structures and with improvements in composition control, further improvements in the perfection of the layering control attainable in oxides is expected.

\section{ACKNOWLEDGMENTS}

We gratefully acknowledge the financial support of the Department of Energy through grant DE-FG02-97ER45638 for the work performed at Penn State and by the College of Engineering and through the NSF FRG grant DMR 9973801 for the work performed at the University of Michigan. 


\section{REFERENCES}

1. Molecular Beam Epitaxy: Applications to Key Materials, edited by R.F.C. Farrow (Noyes, Park Ridge, 1995).

2. Landolt-Börnstein: Numerical Data and Functional Relationships in Science and Technology, New Series, Group III, Vol. 12a, edited by K.-H. Hellwege and A.M. Hellwege (Springer-Verlag, Berlin, 1978), pp. 148-167.

3. F.S. Galasso, Perovskites and High $T_{c}$ Superconductors (Gordon and Breach, New York, 1990).

4. D.G. Schlom, C.D. Theis, and M.E. Hawley in Integrated Thin Films and Applications, edited by R.K. Pandey, D.E. Witter, and U. Varshney, Vol. 86 (American Ceramic Society, Westerville, 1998), pp. 41-60.

5. ATOMICAS ${ }^{\mathrm{TM}}$. Intelligent Sensor Technology, Mountain View, CA.

6. Varian Vacuum Products, Lexington, MA.

7. C.D. Theis and D.G. Schlom, J. Vac. Sci. Technol. A 14, 2677 (1996).

8. C.D. Theis and D.G. Schlom in High Temperature Materials Chemistry IX, edited by K.E. Spear, Vol. 97-39 (Electrochemical Society, Pennington, 1997), pp. 610-616.

9. C.D. Theis, J. Yeh, D.G. Schlom, M.E. Hawley, G.W. Brown, J.C. Jiang, and X.Q. Pan, Appl. Phys. Lett. 72, 2817 (1998).

10. C.D. Theis, J. Yeh, D.G. Schlom, M.E. Hawley, and G.W. Brown, Thin Solid Films 325, 107 (1998).

11. C.D. Theis, J. Lettieri, K.E. Spear, and D.G. Schlom, submitted to Appl. Phys. Lett.

12. The (001) $\mathrm{SrTiO}_{3}$ substrates were etched with a buffered-HF solution to achieve a $\mathrm{TiO}_{2}{ }^{-}$ terminated surface using the processed developed by M. Kawasaki, K. Takahashi, T. Maeda, R. Tsuchiya, M. Shinohara, O. Ishiyama, T. Yonezawa, M. Yoshimoto, and H. Koinuma, Science 266, 1540 (1994).

13. Pseudocubic indices. At the film growth temperature $\mathrm{LaAlO}_{3}$ is cubic. However, on cooling to room temperature it transforms to rhombohedral. The substrate orientation is (110) for the rhombohedral axes.

14. J.H. Haeni, C.D. Theis, S. Trolier-McKinstry, D.G. Schlom, W. Tian, X.Q. Pan, H. Chang, I. Takeuchi, and X.-D. Xiang, submitted to Appl. Phys. Lett.

15. D.G. Schlom and J.S. Harris, Jr. in Molecular Beam Epitaxy: Applications to Key Materials, edited by R.F.C. Farrow (Noyes, Park Ridge, 1995), pp. 505-622.

16. J.H. Haeni, C.D. Theis, and D.G. Schlom, J. Electroceram. 4, 399 (2000).

17. T. Ikeda, J. Phys. Soc. Jpn. 14, 1286 (1959).

18. Phase Diagrams for Ceramists, Vol. 1, edited by E.M. Levin, C.R. Robbins, and H.F. McMurdie (American Ceramic Society, Columbus, 1964), p. 195.

19. Phase Equilibria Diagrams, Vol. 9, edited by G.B. Stringfellow (American Ceramic Society, Westerville, 1992), pp. 126, 130.

20. J.C. Jiang, X.Q. Pan, W. Tian, C.D. Theis, and D.G. Schlom, Appl. Phys. Lett. 74, 2851 (1999) .

21. A. K. Gutakovskii, L. I. Fedina, and A. L. Aseev, Phys. Status Solidi A 150, 127 (1995).

22. S. Thoma and H. Cerva, Ultramicroscopy 53, 37 (1994).

23. W. Tian, D. Jan, X.Q. Pan, J.H. Haeni, and D. G. Schlom (in preparation).

24. B. Aurivillius, Ark. Kemi 1, 463 (1950); 1, 499 (1950); 2, 519 (1951); 5, 39 (1953).

25. B. Aurivillius and P.H. Fang, Phys. Rev. 126, 893 (1962).

26. G.W. Brown, M.E. Hawley, C.D. Theis, J. Yeh, and D.G. Schlom, submitted to J. Cryst. Growth.

27. S.N. Ruddlesden and P. Popper, Acta Cryst. 10, 538 (1957); 11, 54 (1958).

28. J.M. Longo and P.M. Raccah, J. Solid State Chem. 6, 526 (1973).

29. R.J.D. Tilley, J. Solid State Chem. 21, 293 (1977).

30. W. Kwestroo and H.A.M. Paping, J. Am. Ceram. Soc. 42, 292 (1959).

31. G.J. McCarthy, W.B. White, and R. Roy, J. Am. Ceram. Soc. 52, 463 (1969).

32. Phase Diagrams for Ceramists 1969 Supplement, edited by E.M. Levin, C.R. Robbins, and H.F. McMurdie (American Ceramic Society, Columbus, 1969), p. 93. 
33. A. Cocco and F. Massazza, Ann. Chim. (Rome) 53, 883 (1963).

34. M. Drys' and W. Trzebiatowski, Roczniki Chem. 31, 489 (1957).

35. K.R. Udayakumar and A.N. Cormack, J. Am. Ceram. Soc. 71, C-469 (1988).

36. S. Hendricks and E. Teller, J. Chem Phys. 10, 147 (1942).

37. G. Grzinic, Philos. Mag. A 52, 161 (1985).

38. W. Tian, X.Q. Pan, J.H. Haeni, and D.G. Schlom, submitted to J. Mater. Res.

39. Landolt-Börnstein: Numerical Data and Functional Relationships in Science and Technology, New Series, Group III, Vol. 12a, edited by K.-H. Hellwege and A.M. Hellwege (Springer-Verlag, Berlin, 1978), pp. 202-205.

40. K. Szot, C. Freiburg, and M. Pawelczyk, Appl. Phys. A 53, 563 (1991).

41. K. Szot, M. Pawelczyk, J. Herion, C. Freiburg, J. Albers, R. Waser, J. Hulliger, J. Kwapulinski, and J. Dec, Appl. Phys. A 62, 335 (1996).

42. E.S. Machlin and P. Chaudhari in Synthesis and Properties of Metastable Phases, edited by E.S. Machlin and T.J. Rowland (The Metallurgical Society of AIME, Warrendale, 1980), pp. 11-29.

43. C.P. Flynn, Phys. Rev. Lett. 57, 599 (1986).

44. R. Bruinsma and A. Zangwill, J. Physique 47, 2055 (1986). 